\title{
La desorbitación del romanticismo en Italia*
}

\author{
Federico ÁlVAREZ \\ Universidad Nacional Autónoma de México
}

En la creación de conceptos para las ciencias del espíritu deberían esquivarse todas las posibilidades de abuso.

Curtius, Literatura europea y Edad Media latina

\section{Introducción}

El primer problema que nos plantea el estudio del romanticismo es el de la desorbitación del concepto mismo. Al igual que otros conceptos fundamentales de la cultura humanística, el de romanticismo se pierde hoy en un sinfín de definiciones. Su carga significativa ha venido desbordándose más y más desde sus origenes, y hoy sus límites distendidos en todas direcciones hacen casi imposible su uso aun añadiéndole -como han sugerido no pocos críticos- adjetivos clarificadores, o distinguiendo su escritura con inicial mayúscula o minúscula, como han propuesto otros, 0 , en fin, escribiéndolo siempre en plural o entre comillas. Con la perspectiva de dos siglos, la historia del romanticismo es hoy la historia de una desmesura.

El primero en estudiar sistemáticamente este problema fue Arthur 0 . Lovejoy en su famoso ensayo publicado en 1924 en la revista $P M L A$, con el título "On the Discrimination of Romanticism". En este primer ensayo, y luego en otros reunidos en Essays in the History of Ideas (1948) y en The Great Chain of Being (1936; hay traducción al español: La gran cadena del ser. Barcelona, Icaria, 1983), Lovejoy llegaba a la conclusión de que "the word romantic has come to mean so many things that, by itself, it means nothing". La consideraba como un "verbal jack-of-all-trades", y algunos años

* Capítulo de un libro cuyo título podrá ser La desorbitación del romanticismo en la época moderna. El texto aquí publicado corresponde a su Introducción y al capítulo referido parcialmente a Italia. 
después la rechazaba como "useless as a verbal symbol". Era ya entonces una idea muy extendida. En 1941 Valéry decía: "Il est impossible de penser -sérieusement- avec des mots comme classicisme, romantisme, humanisme, réalisme... On ne s'enivre ni ne se désaltère avec des étiquettes de bouteilles". ${ }^{1}$ Y, años más tarde, en su "Situation de Baudelaire": "Je ne vais pas définir ce terme. Il faudrait, pour s'y essayer, avoir perdu tout sentiment de la rigueur".

No obstante, según el profesor británico F. L. Lucas, existían en 1936 once mil trescientos noventa y seis libros sobre el romanticismo, aunque —añadía inmediatamente - "nadie sabe qué es lo que significa". En un ensayo de 1933, T. S. Eliot había indicado ya que la palabra romanticismo recibía su sentido del contexto que la rodeaba, pero esta observación, evidentemente justa, no ayudaba gran cosa a resolver el conflicto. El propio Eliot concluía que "romanticismo, en su sentido más amplio, incluye todo lo que distingue a los últimos doscientos cincuenta años de sus predecesores", y que ello era tan vasto que se debería, "en bien de una mayor claridad y simplicidad, evitar los términos Romanticismo y Clasicismo".

El supuesto progenitor del romanticismo francés, Victor Hugo, dijo en 1869 , ya liberado de sus conservatismos juveniles, que la palabra "romanticismo" era "un mot vide de sens, imposée par nos ennemis et dédaigneusement accepté par nous". Y Musset cuenta en sus Cartas de Dupuis y Cotonet los apuros de dos provincianos en su intento de averiguar qué cosa sería "ese romanticismo que tanta bulla mete". ${ }^{3}$ Francesco de Sanctis, en su sobresaliente Historia de la literatura italiana (1870), no sabe a qué carta quedarse: "El sistema era tan vasto y en él se entremezclaban ideas y tendencias tan diversas, que cada cual podía mirarlo con su lente y tomar lo que mejor le acomodara [...] Se llegó a tal confusión de juicios que hoy mismo no se sabe qué era el romanticismo y en qué se distingue sustancialmente del clasicismo".

En España, Menéndez Pelayo desconfiaba de "esta palabra harto vaga", ${ }^{5} \mathrm{y}$ cuando Roque Barcia se dispuso a exponer su etimología en su famoso Diccionario general etimológico, empezaba confesando: "Entramos sin ambajes en la fórmula de la cuestión, aunque con ninguna esperanza de acierto..."

I Paul VALÉRY, Mauvaises pensées et autres, en Oeuvres, p. 35. También en Oeuvres, t. II (1960), p. 801.

${ }^{2}$ P. VALÉRY, "Situation de Baudelaire", en Oeuvres, t. I (1957), p. 600.

${ }^{3}$ Cit. por Emilia PARdo BAZÁN, Obras completas, vol. 37, La literatura francesa moderna, I. El romanticismo, pp. 154-155.

4 Francesco de SANCTIS, Historia de la literatura italiana (1870), pp. 675-676

${ }^{5}$ Marcelino Menéndez Pelayo, Historia de las ideas estéticas, t. v, p. 166. 
Vemos, pues, que no se trata de un problema reciente. Ya en 1865, cuando Dilthey trataba de definir las ideas de la generación siguiente a la de Kant, Fichte y Goethe, decía: "Podríamos aplicar a esta concepción del mundo el nombre corriente de romanticismo; a menos que se prefiera acabar radicalmente con el abuso que desde hace más de medio siglo se comete con este nombre prescindiendo del nombre mismo".

Ese "más de medio siglo" de abuso retrotrae su origen a 1815, es decir, a la segunda o tercera década -cuando mucho - de los primeros vagidos de la escuela.

Desde la autodenominación misma de la Romantische Schule comienza, pues, su'desbordamiento. Tal vez fue Ludwig Tieck el primero en quejarse:

Esa palabra "romántico" [...] ha provocado muchos malentendidos. Me ha asombrado siempre oír a la gente hablar de poesía romántica como si fuera un tipo especial de poesía. Hay quien trata de contraponerla con la poesía clásica y establecer así una yuxtaposición. Pero la poesía es antes y por encima de todas las cosas poesía, y habrá de seguir siéndolo, siempre y en todas partes, lo mismo si la llamamos clásica que romántica. ${ }^{6}$

El mejor diccionario que por entonces existía (y hoy todavía muy digno de consultarse en muchos conceptos), el famoso Dictionnaire de la Conversation et de la Lecture (1838), se hacía eco de la confusión: "telle chose que l'un admire comme romantique est repoussée par un autre comme classique". "La frecuencia con que desde entonces se ponen comillas a los términos "romántico" y "romanticismo" mide las dudas que asaltan a críticos e historiadores a la hora de usarlos.

Si la contradictoria capacidad significante de estos términos hubiera ya quedado ahíta y, por lo tanto, inútil - como suponen Lovejoy, Valéry, Eliot y tantos más- para cualquier propósito de precisión histórica o estilística, no habría por qué preocuparse de que siguiera proliferando como una mancha de aceite en todas las jergas imaginables. Pero, como decía Julien Benda

6 "That word "romantic" [...] has caused considerable mischief. It has always annoyed me to hear people talk of romantic poetry as if that were a special kind of poetry. People are trying to put it in contrast with classical poetry and so to establish a juxtaposition. But poetry is first and foremost poetry, it will have to be that, always and everywhere, whether we call it classical or romantic". Ludwig Tieck, cit. por Hubert SChrade, German Romantic Painting, p. 7.

7 Artículo "Romantique", Dictionnaire de la Conversation et de la Lecture, 1838, t. XLVII, p. 300 . 
contestando a Valéry, todas las palabras son "étiquettes de bouteilles" y lo necesario es "les faire correspondre à leur contenu", ya que no se piensa sino con palabras. ${ }^{8}$ Las categorías, por muy baqueteadas que estén, por mucho que hayan sido puestas a servir para toda clase de menesteres, tienen un núcleo central durísimo cuando están verdaderamente imbricadas en el complejo juego de relaciones y determinaciones de la realidad histórica concreta. Los conceptos de "romanticismo" y de "lo romántico", haciendo salvedad por ahora de las diferencias entre uno y otro, son categorías reales, objetivas, que corresponden a fenómenos concretos, y sirven, o han de servir, para explicarlos y ponerlos en relación con otros igualmente vivos y concretos. Su desorbitación tiende a anular, y de hecho anula, esa virtud esencial que es parte irrenunciable de toda metodología y de todo propósito de conocimiento.

Aunque Van Tieghem, en su extensa obra sobre el prerromanticismo europeo (1925), renuncie a definirlo, subraya no obstante que en él existe "un fond commun, un substrat réel". También René Wellek, en su ensayo "El concepto de romanticismo en la historia literaria" (1949), insiste en demostrar que "los principales movimientos románticos integran una unidad de teorías" y que la función metodológica de la idea de "periodo" presupone la salvación de aquel concepto. Sus estudios posteriores se han encaminado precisamente a fortalecer este criterio, aunque con escaso eco. Entre los historiadores y teóricos marxistas, la idea de fundamentar el concepto de romanticismo como categoría superestructural válida tiene mayor sustento, sin que ello quiera decir, ni mucho menos, que entre ellos haya en torno al propio romanticismo una valoración unánime. El profesor húngaro István Sôtér, al justificar precisamente el término "romántico", defendía en 1966, en un ensayo sumamente interesante, la idea de que, desde principios del siglo XX, e incluso desde las últimas décadas del siglo XIX, "no encontraremos en la literatura de estos cien años últimos ningún estilo único y homogéneo en el sentido en el que lo fue realmente el romanticismo". De hecho, Sôtér cree descubrir en el romanticismo "el último periodo de estilo homogéneo, o casi homogéneo".

Huizinga no es de este parecer. "El siglo XVIII es el último que se nos ofrece como la realización homogénea y armónica de un propio estilo en todos los órdenes, como unitaria manifestación de la vida en la riqueza y enorme variedad de las formas". Y viene luego un proceso que Huizinga llama de "pérdida del estilo":9 el del XIX.

8 Julien BENDA, La France Byzantine, p. 44.

9 Johan HuIZINGA, Entre las sombras del mañana, Revista de Occidente, p. 211. 
A estas alturas del siglo XXI, parece haber aquí, por un lado, una falta de perspectiva, de distanciamiento, o una insuficiente disposición analítica ante la riqueza del panorama. Pero, de otro lado, no puede dudarse de que hay una teoría estética del romanticismo como la hay del neoclasicismo. Que los románticos, en aras de no sé qué libertad contradictoria y ambigua, teoricen en contra de la teoría, no quiere decir que no la tengan y que no hayan sido ellos mismos quienes la fundamentaron hablando de "móviles del arte" o de una etérea "voluntad artística". En realidad, "estamos hoy -dice Guillermo Carnero- en un momento en que la historiografia literaria se caracteriza por dilucidar la multitud de tendencias que se encubren bajo el engañoso rótulo de "Romanticismo".${ }^{10} \mathrm{La}$ historia de las ideas exige de hecho una dilucidación al respecto.

Pero, frente a estos intentos de precisión metodológica, la marea de la romantización continúa creciendo $\mathrm{y}$, de hecho, justifica el original pesimismo de Lovejoy y de tantos más. Y sus consecuencias son muchos más importantes de lo que parece. "This confusion of terminology - dice Lovejoy-and of thought which has for a century been the scandal of literary history and criticism and is still [...] copiously productive of dangerously undiscriminating diagnoses of the moral and aesthetic maladies of our age".

Sin decirlo de modo explícito, Lovejoy apunta aquí hacia la abrumadora irrupción del irracionalismo en nuestra época, a la que Lukacs Ilamó Die Zerstörung der Vernunft: la destrucción, la demolición, el "asalto a la razón", según expresiva versión de Wenceslao Roces. En ese libro duro, sin matices, escrito bajo los efectos, aún palpitantes, de la hecatombe provocada por el nazismo, Lukacs denunciaba la manera en que el irracionalismo moderno alineaba "en la galería de los antepasados del irracionalismo [...], a grandes pensadores del pasado que, si nos fijamos en la línea esencial de su pensamiento, representaron estrictamente lo contrario de la filosofia irracionalista"."

Tarea paralela a ese alineamiento irracionalizador en filosofia ha realizado y sigue realizando el ensayismo romantizador contemporáneo en la literatura, convirtiendo casi toda la herencia cultural del ser humano en tradición romántica, aun cuando muchos de los escritores aducidos representen lo contrario de la corriente romántica. El postestructuralismo parece ser un nuevo caldo de cultivo para la prosecución de la tradición romantizadora. En la Introducción a una nueva recopilación de ensayos sobre crítica ro-

"Cf. Guillermo Carnero, "Sobre Agustin Durán", en Insula, núm. 404-405.

" Georg LUKACs, El asalto a la razón. La trayectoria del irracionalismo desde Schelling hasta Hitler, p. 99. 
mántica, Romantic Revolutions, Criticism and Theory, sus editores afirman que "much of the linguistic, immanentalist, or relational thrust of the leading new theories has been aimed most tellingly at conceptions of literature that are nothing if not Romantic".

Antes de buscar las causas de este desborde ideológico que tanto viene influyendo en la historia de nuestras ideas, resulta imprescindible $-y$ sumamente iluminador- empezar por una relectura ejemplar (es decir, forzosamente parcial) y descriptiva del desbordamiento mismo.

La romantización ha tenido, desde finales del siglo XVIII, dos grandes momentos. Analizando superficialmente las extensas bibliografias que sobre el tema nos brindan los libros de Paul van Tieghem, Henri Peyre y A. Farinelli, resulta fácil señalar la década de los años veintes ( $y$ la de los treintas) del siglo XX como la etapa climática de ese intento. No es ni mucho menos casual el hecho de que las últimas décadas (de los años cincuentas en adelante) disputen ese mérito a la década de entreguerras. En tercer lugar, habría que echar la vista atrás y subrayar el renovado intento romantizador que se prudujo en Europa a finales del siglo XIX, el romantic revival del decadentismo finisecular; y, por último, el más esencial y original —aunque. tal vez, el menos consciente- esfuerzo romantizador universalizante de los primeros y verdaderos románticos de comienzos del siglo XIX, en Alemania.

Los primeros románticos, en el primer tercio del siglo XIX, empezaron por romantizar la época medieval cristiano-caballeresca, de la que se sentían íntimamente familiares y a la que convirtieron en la época romántica original por excelencia; al mismo tiempo romantizaron los siglos de oro (Calderón, Shakespeare, etcétera), en donde encontraron los primeros escritores cabalmente "románticos", y, por último, hicieron de los diversos folclores nacionales, de las canciones y coplas populares, y del arte primitivo de países exóticos (antiguas literaturas orientales en particular), el sustrato último de toda autenticidad romántica. Generaciones posteriores acabaron por constituir un difuso prerromanticismo (todavía no se le llamaban así) con todos los escritores reacios a la estrechez normativa "clásica" de los siglos XVII y XVIII, y no faltó tampoco quien los hiciera llanamente románticos.

El romantic revival de finales del siglo XIX y los vanguardismos del XX completaron la tarea: el presente era romántico y el futuro no podia dejar de serlo. La mayoría de los autores se declararon descendientes del romanticismo e hicieron de este movimiento la línea única y universal del arte verdadero.

En su Historia de la poesía y de la elocuencia desde el fin del siglo XIII (cuyos volúmenes aparecieron entre 1801 y 1805), F. Bouterwerk considera 
ya como autores "románticos" a Shakespeare, Calderón, Cervantes, Ariosto y Tasso. No se trataba de una romantización ideológica consciente sino de un desarrollo digamos "natural" del uso del adjetivo "romántico" originado en el siglo anterior y muy bien historiado por Lovejoy. Bouterwerk no pertenecia a la Romantische Schule pero, a pesar de su acendrado apego a las ideas de la Aufklärung, era amigo de A. G. Schlegel, cuyo talento admiraba y de quien bien pudo haber tomado muchas ideas. El primer motivo de la romantización de aquellos cinco enormes escritores clásicos estaba -como más adelante veremos con mayor detalle - en la relación bilateral que Schlegel, Novalis y, después, Schelling y Hegel (aunque con diferentes proyectos), establecieron entre cristianismo y romanticismo. Es más, los románticos alemanes, al traducir las tragedias de Shakespeare, el teatro de Lope y Calderón, los poemas de Tasso y Ariosto y el Quijote, pretendieron haber descubierto, en verdad, los valores auténticos —cristianos y románticos-de estos autores y obras.

\section{En Italia}

Dante y Ariosto fueron los primeros autores italianos mencionados en la primera nomenclatura romántica realizada en Alemania, pero no precisamente con entusiasmo. La literatura italiana se ha resistido siempre a las romantizaciones. Los primeros románticos alemanes la menospreciaban, y no lo ocultaban. Tasso les gustaba menos que sus dos grandes compatriotas. J. A. Symonds lo ha explicado en función del eclecticismo abiertamente profesado por el autor de la Jerusalem libertada. Entre "antiguos" y "modernos" (Symonds transporta abruptamente el viejo pleito al de "clásicos" y "románticos") Tasso había "introducido un nuevo principio en la discusión [...]: el del sentido común, el buen gusto y el instinto. Tasso venía a,decir: no existe ninguna discrepancia esencial entre el arte clásico y el romántico; los dos tienen cualidades positivas y en ambos se pueden descubrir defectos". El Rinaldo, poema escrito a sus dieciocho años, es precisamente el intento de "combinar los atractivos de lo romántico con la sencillez de la poesía épica" (a pesar de lo cual Symonds lo llama "poema romántico"). "Como artista - concluye Symonds-, Tasso pertenecía al viejo orden de cosas [...]; como cristiano, su alma estaba con el nuevo orden de cosas". Como artista, clásico; como cristiano, romántico. El absolutismo lírico de los primeros románticos alemanes no podía aceptar fácilmente estas veleidades eclécticas. 


\section{Romantización de Tasso: I. El placer en el dolor}

Y es que el romanticismo de Tasso es, según Mario Praz, de otro tipo. No es ya sólo el cristianismo y el gusto por el romance y la canción popular los que lo determinan, sino, sobre todo, "el uso de la idea del placer en el dolor". Es tema muy interesante que he desarrollado en otro lugar. También Heine tenía al romanticismo, y no de modo plausible, como "une glorification de la volupté de la douleur". Si tal fuera, en verdad, un motivo especificamente romántico, no hay duda de que el origen del romanticismo habría que echarlo muy para atrás, hasta aquella disciplina del sufrimiento que los griegos apolíneos consideraban como "merced de los dioses", o hasta el coloquio platónico de La República en el que Sócrates habla del "gemir a su gusto" del hombre de condición pusilánime y femenina; y habría que seguirlo interminablemente en todas las épocas y escuelas, pasando por el "dolor sabroso" de santa Teresa, por la exclamación extática de san Juan de la Cruz ( OOh, llama de amor viva, / qué tiernamente hieres...!), hasta la "aguda espina dorada" de Machado o los "dolores amables" de Lorca. ¿Dónde, pues, su legítima faceta romántica? La "adoración del dolor" nacía, en opinión de Carlyle, como un elemento esencial en el cristianismo, y ésa es evidentemente la tradición que lo llevó al romanticismo. El crítico argentino Arturo Capdevila lo ha expuesto con claridad: "la ética cristiana del dolor se convierte en el romanticismo en la estética del dolor [...] El poeta romántico se apropia el léxico de la Pasión". Con lo que el "placer en el dolor" de Tasso sólo resulta romántico en la medida en que se convierte en faceta del carácter místico-cristiano del romanticismo (y de un misticismo no siempre necesariamente cristiano).

\section{Romantización de.Tasso: II. El no-sé-qué}

Emparentada con este "placer en el dolor" de Tasso, y también indicando supuestamente su romanticismo, estaría, según Praz, la recurrencia al "non so que", a la sensibilidad ambigua y anhelante de lo desconocido, tan curiosamente frecuente en Tasso desde su Rinaldo juvenil. Pero de nuevo ese non-so-que (lo inefable) tiene un extenso currículum que no siempre resulta romántico. No es éste el lugar para seguirlo interminablemente. Dámaso Alonso habla de una coplilla española medieval anónima, probablemente anterior a Tasso ("por sólo la hermosura / nunca yo me perderé / sino por un no sé qué / que se halla por ventura") y recuerda, por supuesto, la queja de la Esposa en el Cántico espiritual de Juan de Yepes (“...y déxame muriendo 
un no sé qué que queda balbuciendo") con el hallazgo de esos tres ques seguidos. Pero lo asombroso es que este famoso tranquillo lírico tiene enorme difusión en casi todas las lenguas literarias sin dejar de lado al latín. No entraremos en si es justo o no traducir - como han hecho muchos traductores muy autorizados- nescio quid y aliquid (en Virgilio, Lucrecio, Ovidio, Horacio o Cicerón) por un no-sé-qué que en modo alguno podría ser romántico. Pero, ¿acaso hay romanticismo en Ronsard (1524-1585) cuando escribe: "Pein-la moy doncq, qu'elle semble parler, / Ores sou-rire, ores embasmer l'air / De ne scay quelle ambrosienne haleine". O: "Puis avecques tout cela / encor d'avantage elle a / Je ne scay quelle feintise / Ne scay quelle mignotise, / Qui fait que je l'aime mieux / Que mon coeur ny que mes yeux"? ¿Lo hay en Montaigne cuando dice: "nous sentons au dedans de ne scay quelle aigredouce poincte de volupté maligne a voir souffrir autruy"...? ¿Lo hay en Corneille (Rodogune, acto I, escena V): "Il est de noeuds secrets, il est des sympathies, / Dont par les doux rapport les âmes assorties / S'attachent une a l'autre et se laissent piquer / Par ces je ne sais quoi qu'on ne peut expliquer"? ¿Lo hay en el propio Tasso, cuando Clorinda (canto XII) piensa en cómo reducir a cenizas los artefactos de Olindo y comunica a Argante sus propósitos: "Buona pezza è, signor, che in sè raggira / Un non so che d'insolito e d'audace / La mia mente inquieta"?

Los ejemplos son innumerables y el tema ha provocado desde el siglo XVII el suficiente interés como para que haya diversos ensayos teóricos dedicados explícitamente al no-sé-qué: el del dominico francés Bouhours (1687?) es probablemente el primero; le siguen el del padre Feijóo (1778), Montesquieu (en su ensayo sobre el gusto, publicado póstumamente), Menéndez Pelayo (en sus comentarios sobre Feijóo), Symonds (1875, sobre Tasso), Praz (1974, sobre Tasso también) y más recientemente Michel Charles ( $L$ 'arbre et la source, 1985, sobre Bouhours). Dificil resumir en pocas palabras la interesantísima riqueza de estos varios centenares de páginas. Sólo Menéndez Pelayo, Symonds y Mario Praz dan carácter romántico a esta intrigante frase lexicalizada.

Para Menéndez Pelayo el discurso del padre Feijóo sobre el noséqué (Feijóo acaba sustantivándolo en una sola palabra) "es un verdadero manifiesto romántico". Pero enseguida añadía con genial atisbo (que, como en tantos otros casos, no desarrolló): "a menos que no queramos considerarle como el último eco de otras doctrinas de libertad literaria, generalmente aceptadas en la España del siglo XVII..." Pero, a la postre, aunque de manera acaso metafórica, acaba romantizando: " ¿Cómo no reconocer [...] en esta especie de insubordinación erigida en sistema, en este romanticismo anticipado, el último fruto de la antigua crítica española...?" Y los ejemplos que 
pone como antecesores de Feijóo (Vives, Pinciano, González de Salas, Herrera "el Divino", Alfonso Sánchez, Barreda, Caramuel) son los mismos con los que el propio Menéndez, en otros textos, ha ido perfilando el eclecticismo español.

Symonds también romantiza a Tasso. Con el non-so-ché Tasso expresa "esa emoción nueva [...], vaga, difusa, rehuyendo todo contorno claro". Tasso es así "el primer artista auténticamente sentimental de los tiempos modernos". Pero también aquí hay reservas importantes: el autor de la Gerusalemme "aspiraba a acatar las reglas clásicas del arte, pero sin sacrificar a ellas el encanto de la variedad y el deleite que los episodios y las maravillosas aventuras brindan a un auditorio moderno..." Se esforzaba "por realzar su estilo mediante la imitación de los poetas latinos". En definitiva - califica Symonds- Tasso es "un poeta ecléctico".

Praz, siguiendo, según él mismo dice, a Ferruccio Ulivi, considera a Tasso "el heraldo de la sensibilidad ambigua del periodo barroco e incluso del romántico; realmente, su anhelo de lo desconocido, el non so ché, lo exótico, y su sentido de la soledad del hombre, son rasgos románticos".

¿Y el famoso know-not-how en Locke? ¿Y el je-ne-sais-quoi en Ronsard, en Théofile Silvestre, en Corneille, en Boileau, en Mère, en La Fontaine, en Montaigne, en Fenelon, en Fontenelle, en Voltaire, en Marivaux, en Marmontel...? La lista es infinita en la literatura francesa. "Es el prerromanticismo", según el dilatado estudio de Monglond; pero, según Curtius (I, 231), son los "tópicos de lo indecible", tan frecuentes en los panegíricos clásicos latinos; "il est un piece nécessaire de la machine classique", según Michel Charles.

¿Y en la literatura contemporánea? Desde Eça de Queiroz hasta Juan Ramón Jiménez, desde Amado Nervo hasta Roger Caillois, desde Essenin (nechto, tan curiosamente parecido al nescio latino, o chtó-to) a Ungaretti, no parece haber poeta ni prosista que no haya echado mano alguna vez del famoso no$s e ́-q u e e^{12}$ No parece justo adjudicarlo en propiedad privada al romanticismo.

\section{Romantización paralela de Ariosto}

En 1802, casi al mismo tiempo que Bouterwerk, Barante, en su Tableau de la littérature francaise au XVIIIe siècle,$^{13}$ convierte a Ariosto en el polo

${ }^{2}$ Del alemán puede traducirse igualmente "sie hat ein gewisses etwas": ella tiene un no-sé-qué.

${ }^{13}$ Barante, Tableau..., p. 71. 
diametral de Homero. Al enjuiciar La Pucelle de Orleans dice de Voltaire que, en esa obra, "l'auteur est resté aussi loin de l'Arioste que d'Homère", es decir, muy eclécticamente, a mitad de camino entre la cultura románticocristiana y la clásico-pagana. A esa cultura romántico-cristiana se la identificaba sociológicamente con la época "caballeresca" y el Orlando furioso era de manera casi forzosa el paradigma literario de una y de otra. Pero el clasicismo, la tradición clásica, no podía quedar tan alejada como querían Bouterwerk y Barante. Estaba ahí también, en el Orlando, en la medida en que Ariosto estaba en el Renacimiento. Agustín Durán lo vio en 1849, en su prólogo al Romancero general: "escribieron los italianos [...] aquella multitud de poemas caballerescos precursores del Orlando furioso, en el cual se reasumieron todos los elementos compatibles de la poesía clásica con la románica, hija del estado social de los siglos medios". ${ }^{14}$ Para Durán ya no estaba Ariosto en el polo opuesto a Homero; había un lazo, qué duda cabe, que lo unía a la poesía clásica. Lo específicamente "románico" (lo "romántico") eran los siglos medios.

Pero Symonds, en el último cuarto del siglo XIX, tiene ya otros motivos para romantizar a Ariosto, aunque tampoco pueda hacerlo plenamente. Romantiza, primero, a Ariosto (y por igual motivo, a Tasso) por el uso del "idilio" del que ambos echan mano, "junto al mal gusto de la bucólica artificial, de sus absurdos disfraces, de su plétora de lágrimas, encontramos aquí la tiranía de los besos, el anhelo de la Edad de oro y, en general, todo el aparato de este género operístico". ${ }^{15}$ Pero, ¿no era el idilio un género clásico y neoclásico, "ingenuo" según la caracterización de Schiller? Otra razón sería el gusto de ambos por los romances medievales, y su rechazo de las "reglas" clásicas predominantes ya en el Renacimiento.

Pero para los románticos alemanes lo fundamental era la esencia religiosa de sus obras (que a Symonds le parece, sin embargo, poco auténtica), su virulencia contra el paganismo (sobre todo en el caso de Ariosto) en pleno siglo renacentista. Según Symonds, "el poeta romántico es el que, creando un mundo puramente imaginario, trata las ficciones de su fantasía como si fueran realidades". En tal sentido, Ariosto prefirió "el estilo romántico al estilo heroico de poesía", al hacer del Orlando furioso "una obra de pura fantasía". No obstante, Ariosto "no cree realmente en el mundo caballeresco y donde Boyardo procede con la mayor seriedad, Ariosto bromea". (Para Symonds "mundo caballeresco" es igual a "mundo romántico".) Es más, "los elementos románticos de lo maravilloso y lo exagerado forman la base de su poema, pero la

14 Agustín DURÁN, "Prólogo", Romancero general, t. I, p. XI.

15 J. A. SYMONDS, El Renacimiento en Italia, t. II, p. 819. 
superestructura no puede ser más natural". Symonds pone vela a Dios y hurgón al diablo. Y es que en Ariosto se da —dice Symonds agudamente- la premonición de Swift y de Hoffmann. Una vez más, una personalidad bifronte, ecléctica. "Nunca las prudentes lecciones de la sabiduría de la vida han sido profesadas desde una escena de tan palpable inverosimilitud". ${ }^{16}$

En un ensayo sumamente sugestivo, Boris G. Kouznetjov ha relacionado también la sonrisa irónica de Ariosto con la de Cervantes, otra víctima noromántica de la romantización. "Es la sonrisa —dice-que el Renacimiento y los tiempos modernos le dirigen a la Edad Media [...], sonrisa asociada a la presencia intuitiva de la nueva reflexión sobre el mundo y sobre el hombre mismo". ${ }^{17} \mathrm{Y}$, lo que es más importante, a la vista de las notas marginales de Galileo (1564-1642) al Orlando furioso, en las que "Galileo adopta la sonrisa de Ariosto...", "tan parecida a la de Cervantes en Don Quijote". Kouznetjov establece la "relación indubitable entre la poética de Ariosto y la transición de la lógica de la ciencia nueva [...] hacia una visión universal causal del mundo. Esta representación diferencial [...] se vuelve evidente y clara en el siglo XVIII, pero ya en el siglo XVII se había convertido, según Galileo, en el ideal del conocimiento científico". Que en el siglo XVII esa perspectiva no fuera más que una aspiración, un "arrebato emocional", y que, en efecto, no pudiera ser más que un arrebato emocional, no romantiza para nada a Ariosto ni a Galileo, sino que da a la "ruptura metalógica" esperada una dimensión antitradicional, incluso no clásica, en la que -como dice Kouznetjov - "la poética de Galileo, poética de la lógica, extraía su impulso de la lógica de Ariosto, lógica de la poesía". ${ }^{18}$ Kouznetjov establece incluso una relación secuencial entre el mundo de Ariosto y el de Malebranche y Spinoza, un siglo después, relación en la que cabría Cervantes.

Symonds está de acuerdo también en que Ariosto "no cree realmente en el mundo caballeresco y (repetimos) donde Boyardo procede con la mayor seriedad, Ariosto bromea". No con la intención satírica de Cervantes sino "con una ironía que todo lo invade y que no lleva en sí aguijón alguno". Pero Ariosto no romantiza a la Edad Media. Los elementos románticos de Orlando furioso, según Symonds, son "lo maravilloso y lo exagerado", "pero la superestructura no puede ser más natural". ${ }^{19}$ ¿No pasa lo mismo con el Quijote dejando aparte lo de la ausencia del aguijón?

I6 Ibid., t. II, pp. 193-194, 196-197, 200.

${ }^{17}$ Boris G. KouzNETJov, "Estética de la ciencia no clásica", en Diógenes, núm. 115 , pp. 89-90.

18 lbid., p. 90.

19 J. A. SYMONDS, op. cit., t. 1I, p. 197. 
Hegel había visto ya que "en Italia y en España, al agonizar la Edad Media, Ariosto y Cervantes empezaron a volverse en contra de la caballería", ${ }^{20}$ lo cual, desde el propio punto de vista romántico, los desromantizaba y los convertía en lo que fueron, clarísimos renacentistas.

El Orlando es, sí —dirá enfático Symonds-, un poema romántico, pero por razones estilísticas, formales: "la finura de sus eslabones de engarce y el constante cambio de escenografia". ${ }^{21}$ Si Ariosto es romántico, al igual que Tasso, es porque, para Symonds (que escribe en la segunda mitad del siglo XIX y en Inglaterra), el romanticismo inglés es (como para la mayoría de los críticos ingleses del siglo XIX) un romantic revival ("denominación equivoca" según Priestley) del verdadero y primer romanticismo, el de los siglos de oro italianos y españoles, libres siempre ( $y$ en lo mejor) de las ataduras clásicas (aunque Tasso, respetándolas parcialmente en muchas de sus obras, "declarábase ecléctico") ${ }^{22}$ En sus Diálogos sobre el arte de la poesía escritos en su juventud ese romanticismo está hecho de libertades formales y, en lo sustancial, de irrupciones emocionales (el placer en el dolor, el no-séqué, la tirania de los besos...).

Pero hay aquí una evidente confusión de niveles categoriales cuando se toma al romanticismo como un estilo. Por ese agujero, el romanticismo se escapa ciertamente de la historia. Todo el capítulo de Symonds sobre Ariosto y Tasso y la "escuela romántica italiana" de los siglos XV y $\mathrm{XVI}^{23}$ se basa en la idea clasificatoria de un "estilo romántico" paralelo, por ejemplo, al estilo heroico, al burlesco, o al satírico, y cuya especificidad consistiría en el propósito de "asombrar, fascinar, divertir e interesar a los lectores" mediante la creación de "un mundo puramente imaginario" [...] "con el mayor apego a la verdad de la naturaleza y bajo la luz fuertemente coloreada de la imaginación artística" ${ }^{24}$ La concepción historicista de Wellek, la implicada en la categoría de "periodo", quedaba estilísticamente burlada. Otro enemigo, el psicológico (¡una psicología romántica!), vendría más tarde a intentar una nueva deshistorización del romanticismo.

${ }^{2 n}$ G. W. F. HeGEL, Werke, t. X, pp. 231 y ss. Cit. por Ernst Bloch, Sujeto-objeto. El pensamiento de Hegel, p. 273.

21 J. A. SYMONDS, op. cit., t. It, p. 201.

22 Ibid., t. II, p. 781.

${ }^{23}$ Ibid., t. II, p. 816.

${ }^{24}$ Ibid., t. II, pp. 193-194. 


\section{Romantización de Maquiavelo}

Maquiavelo había dicho: "El mundo pertenece a los espíritus fríos". Parecia, por esto y por tantísimas cosas más - su odio al papado, su rechazo de lo medieval, su cinismo, su amoralismo, su defensa de la hipocresía política, el maquiavelismo, en una palabra-, una figura impermeable a todo romanticismo. Pero, a pesar de esa frialdad paradigmática, Maquiavelo tenía una profunda sensibilidad patriótica (florentina, más que italiana, pero también italiana), sensibilidad que la romantización irracionalizadora aprovechó de manera sutil.

Según Alfred von Martin, en su excelente Sociología del Renacimiento, Maquiavelo sentía la añoranza nostálgica de los "virus ilustribus" a los que había cantado Petrarca, y con cuyos versos da fin a El príncipe:

Virtù contra furore

Prenderà l'arme, e fia'l combatter corto:

Che l'antico valore

Negl'italici cuor non è ancor morto. ${ }^{25}$

La antigua virtù era "el antiguo valor" romano anterior al Imperio, valor que se quería ver renacer para arrojar a los franceses y españoles ("los bárbaros") de Italia:

De la situación presente - dice Von Martin-y de la conciencia de la décadence de la propia época, deriva en Maquiavelo el concepto romántico del renacer de aquella virtù romana [...] En ese romanticismo (vencer queremos...) coinciden de manera muy sospechosa Maquiavelo y Petrarca, el poeta y el soñador politico. En Maquiavelo se da el racionalismo romántico, la creencia de que, con los medios de la "organización artificial" todo puede implantarse... ${ }^{26}$

Maquiavelo es político y piensa en el poder de un principe providencial italiano que ya no va a aparecer, y en él predomina esa nostalgia de la

${ }^{25}$ Petrarca, iltalia mia!, canto XVI, 93, con el que da fin El príncipe; cit. y traducido en Hans KOHN, Historia del nacionalismo, p. 119; en la Historia de la literatura italiana de De Sanctis, ed. cit., p. 421 ; y en los Escritos sobre Maquiavelo, de Chabod, p. 408: "La virtud contra el furor/ tomará las armas; y será corto el combate, / pues el antiguo valor / en los itálicos corazones aún bate".

${ }^{26}$ Alfred von MARTIN, Sociologia del Renacimiento, pp. 101-102. 
virtù pasada. Petrarca, por el contrario, practica un "romanticismo inofensivo", pasadista y arrimado al poder, cualquiera que éste sea.

Para Maquiavelo la virtù consistía - dice Von Martin- en "el máximo aprovechamiento de todas las fuerzas potenciales, la eliminación de todos los elementos emotivos en un mundo puramente intelectual y calculador...", "aunque - añade más adelante-más bien concebida en sentido democrático como abnegación patriótica y espíritu de sacrificio". ${ }^{27}$ Burckhardt recoge expresiones de la época en las que se trasluce la identificación entre virtù e importancia social, celebridad, "fuerza insigne". ${ }^{28}$ Para Symonds era "la valentía, el talento y el valor personal de quien sabe llevar a cabo lo que se propone sea lo que fuere", sinónimo de la areté griega: "la cualidad que hace al hombre"; ${ }^{29}$ para Francesco de Sanctis, es "ahuyentar todas las vanas apariencias y dirigirse hacia el objetivo con lucidez de mente y firmeza de voluntad", ${ }^{30}$ y para Johannes Bühler, "la capacidad burguesa", la madurez, que él identificaba con Lutero. ${ }^{31} \mathrm{Nada}$ de esto tiene un adarme de esencia romántica. Quien más metódicamente estudió esta cuestión crucial fue E. W. Mayer, en 1912 (Machiavellis. Geschichtsauffassung und secis Begriff "virtü"), a quien Chabod resume eficazmente: "La 'virtud' de Maquiavelo no es, como para nosotros, una cualidad 'moral', sino energía, facultad de querer y de hacer, prescindiendo del contenido 'moral' de esta energía y facultad". ${ }^{32}$

Con el sacco di Roma (por alemanes y españoles, en 1527) "acaba el sueño romántico evocador" de Maquiavelo, concluye Von Martin. Lo romántico maquiavélico era, pues, tan sólo una nostalgia patriótica en la que apenas se esbozaba nebulosamente (Maquiavelo sentía todavía más la atracción de la región propia - Florencia- que la de toda la península) la unidad de Italia.

El abuso del término "romántico" lleva a Von Martin a suponer -bien es verdad que con grandes reservas sobre la honestidad ideológica y el desprendimiento de sus cultivadores-que "en los círculos influidos por el humanismo se da también un romanticismo republicano tipo Bruto-Casio", es decir, un "apasionado pathos de libertad..." "cuya expresión más digna se encuentra en Bocaccio y Salutati". (Con lo que, en passant, queda sem-

${ }^{27}$ Ibid., pp. 61, 81 .

28 Jacob BURCKHARDT, La cultura del Renacimiento en ltalia, t. I, pp. 112, 159.

${ }^{29}$ J. A. SYMONDS, op. cit., t. I, pp. 106-107, 391.

${ }^{30} \mathrm{~F}$. de SANCTIS, op. cit., p. 429.

31 Johannes BUHLER, Vida y cultura en la Edad Media, pp. 112, 106 y ss.

32 Federico ChABOD, "El secretario florentino" (1953), en F. CHABOD, Escritos sobre Maquiavelo, p. 58. 
brada la romantización de Bruto y Casio... y de Bocaccio y Salutati, en función del pathos de libertad y del republicanismo, es decir, de la romantización irracionalizadora, ya muy adelantada en esos años, de la Revolución francesa.)

Inútil fue la protesta de T. S. Eliot ante la romantización de Maquiavelo. En su ensayo "Niccolo Machiavelli" Eliot afirma que "his message has been falsified by persistent romanticism ever since his death [...] He is always placed a little askew".

La romantización de Maquiavelo pudo originarse en los notables ensayos que desde 1925 escribiera Federico Chabod acerca de El principe. Chabod describe "la declinación de la virtud política en la sociedad comunal" italiana en la época de Maquiavelo, y la "posterior y definitiva aniquilación de la conciencia popular". ${ }^{33}$ Es así como en Maquiavelo surge, en efecto, la nostalgia "que suscita la imagen de la felicidad de la Italia perdida...", "la contemplación de aquella Roma antigua que supo convocar en torno suyo a la península entera". Aquella unidad había quedado convertida en una "melancólica aspiración" y "Maquiavelo se detiene con apasionada intensidad en la monarquía italiana, en la antigua unidad destruida". Ante la vileza de las masas "Maquiavelo se ha aferrado a la virtud individual", una virtud "libre de determinaciones" éticas, indetificada con "la energía necesaria para actuar con éxito". ${ }^{34} \mathrm{Y}$ el príncipe sería "el redentor que reparará los pecados de los antiguos señores". "Era — concluye Chabod- un sueño bello, audaz, formidable, pero sueño al fin". Pero Chabod se cuida mucho de prolongar la definición de esta nostalgia maquiavélica y llamarla "romántica".

\section{Romantización del humanismo renacentista}

Maquiavelo hacía causa común "romántica" con Petrarca. Ya lo hemos visto. Para Von Martin el humanismo renacentista, aunque nacía contra el medioevo, arrastraba de él no pocos elementos: entre ellos el romanticismo. El humanismo era una restauración... y un romanticismo. Nada faltaba, pues, para romantizar llanamente al Renacimiento, y asi lo hizo Von Martin en su

${ }^{33}$ F. ChABod, “Acerca de El principe, de Nicolás Maquiavelo" (1925), en F. СНАBOD, op. cit., p. 58.

${ }^{34}$ Cf. H. C. F. Mansilla, "Machiavelli y Hobbes, filósofos de la historia en la perspectiva de la Escuela de Frankfurt", en Introducción a la teoria crítica de la sociedad. 
ensayo "Petrarca und die Romantik der Renaissance" y en su Sociologia del Renacimiento. Era un "libre humanismo literario [...] ejemplarmente representado por Petrarca y luego por Poggio, Valla, Eneas Silvio, Filelfo e tutti quanti". ${ }^{35}$ Este humanismo "significa una cierta 'afinación' del alma, para la cual presta su nombre sagrado Platón..." Es también "un refugiarse en el pasado 'ideal' [...] como intelectuales reaccionarios que buscan su salud en la huida hacia la Antigủedad". "El humanista romántico - prosigue Von Martin - se retrae de la luz demasiado clara y cruda para él de una civilización racional a la semioscuridad de un mundo de ensueño, irreal, es decir, al mundo literario (lo más retrospectivo posible), en el cual puede construir su mundo nostálgico". Y resume, como si estuviera hablando del siglo XIX: "Frente a la antigua clase clerical del saber y frente a la nueva clase burguesa y propietaria [...], se afirma un cierto idealismo cultural romántico, que representaba un irracionalismo ("superior") de ideales puramente espirituales sin posible aplicación práctica". ${ }^{36}$

Ese irracionalismo es de una coherencia intelectual absoluta, la que constituye el "asalto a la razón" del que se queja Lukacs. El nuevo "romántico del espiritu" sustituye al "romántico de la acción" (que era el medieval), "pues ninguna época - concluye Von Martin- puede vivir sin una cierta clase de irracionalidad". Esta vez, sin embargo, como el Renacimiento es una época racionalista, "la irracionalidad se desplaza hacia la periferia, y no puede afirmarse, como en la Edad Media, en el núcleo vital y en el centro espiritual de una época". ${ }^{37} \mathrm{De}$ un romanticismo medieval hegemónico y central, pasamos en la época renacentista a un romanticismo humanista periférico, que se automargina — diriamos hoy-, y reaccionariamente se refugia en la soledad y en la "antigüedad"... clásica.

Nos equivocaríamos si pensáramos que todo lo demás es antirromántico. Frente al romanticismo pretrarquista se da (como en el siglo XIX) el otro romanticismo activo, social, político: el de Bruto-Casio (romanticismo de la idea republicana contra el imperio cesáreo). El panorama parece estar enteramente ocupado por el romanticismo.

Contradictoriamente - a primera vista-, aquel humanismo romántico, y Petrarca en primer lugar, "manifiesta sus intenciones reaccionarias en el anacronismo de la restauración del "latín clásico"'; y, en su doble aislamiento (psicológico y linguístico) de la realidad, encuentran "el descanso de un idilio bucólico, donde impera la nobleza de lo clásico [...] en el silen-

\footnotetext{
${ }^{35}$ A. von MARTIN, op. cit., p. 8.

36 Ibid., pp. 82-83.

${ }^{37}$ lbid., p. 86.
} 
cio de su gabinete de estudio [...] en el que puede vivir el mundo de fantasía de su clasicismo". ${ }^{38}$ No hay contradicción alguna; otros romantizadores habían llegado ya al colofón inescapable: lo clásico era también, romántico.

\section{Romantización de Petrarca}

La romantización se fijó, pues, más atrás, en Petrarca (1304-1374). Ya Tassoni, en el inicio de la "querelle", unía a Petrarca con los "antiguos", con Aristóteles y Homero, contra los "modernos" (que, en nuestro caso, eran Tasso [1544-1595] y Ariosto [1474-1533]).

En la historiografía moderna resulta frecuente negar la adscripción absoluta de Petrarca al medievalismo y afirmar su complementaria herencia pagana. Según Burckhardt, "en Petrarca descubrimos aún un estado de ánimo que divide el interés entre la Antigüedad clásica y la cristiana [...] insinuándose la preferencia de Petrarca por la Roma pagana".

El paso siguiente lo da Huizinga al emparentarlo, saltando dos siglos, con Erasmo y definirlo, sin embargo, abiertamente como "el romántico de la Antigüedad".

Petrarca fue, ante todo, para sus contemporáneos, un Erasmo avant la lettre, un multiforme y delicioso autor de ensayos sobre la moral, la vida, un epistológrafo de buen tono, el romántico de la Antigüedad, con su Liber de virus illustribus, y los Rerum memorandum libri $\mathrm{l}$. Los temas que trataba, De contemptu mundi, De otio religiosorum, De vita solitaria, ajústanse aún completamente a las ideas medievales.

Ortega y Gasset también cree en el romanticismo de Petrarca, pero sus motivos son muy otros. Véase: "El primer germen de romanticismo aparece en Petrarca [...] acaso la primera criatura que cultivó el alpinismo con intención contemplativa". No se crea que es una boutade típica del ensayismo orteguiano. Herbert Read lo repite en 1954: "Fue el primer hombre que escaló una montaña con el único objeto de contemplar la vista desde ella". ${ }^{39}$ Es el disparate romantizador.

El argumento de Huizinga es, aunque desorbitado, más considerable. El "romanticismo" de Petrarca, como el de Maquiavelo, se afilia, en definitiva,

38 Ibid., pp. 83-84.

${ }^{39}$ Herbert READ, "La revolución romántica" (1954), en La décima musa. Ensayos de critica, p. 162. (Sospecho que antes de Ortega y Read hay una fuente común.) 
a un pasadismo nostálgico de los "varones ilustres", un poco a la manera también en la que, un siglo después, repetirá insuperablemente Jorge Manrique en las Coplas a la muerte de su padre. Si el "cualquier tiempo pasado fue mejor" es sello romántico, romantiza a todas las edades, y deshistoriza una vez más, desorbitándola, toda posible concepción moderna del romanticismo.

\section{Bibliografía}

BARANTE, Guillermo Próspero, barón de, Tableau de la littérature francaise au XVIIIe siècle. 6a. ed. París, Charpenter, 1845.

BENDA, Julien, La France Byzantine. París, 1932.

BÜHLER, Johannes, Vida y cultura en la Edad Media. Trad. de Wenceslao ROCES. México, FCE, 1946. (1 ra. ed. alemana, 1931.)

BURCKHARDT, Jacob, La cultura del Renacimiento en ltalia. Barcelona, Iberia-Orbis, 1985. 2 tt. I. Prólogo de J. BOfILL Y FERRO. Trad. de Jaime ARDAL. (1 ra. ed. alemana, 1860.)

CARNERO, Guillermo, "Sobre Agustín Durán", en Ínsula, núm. 404-405. Madrid, jul.-ago. de 1980.

CHABOD, Federico, "Acerca de El príncipe, de Nicolás Maquiavelo" (1925), en F. CHABOD, Escritos sobre Maquiavelo. Trad. de Rodrigo RuZA. México, FCE, 1984. (1 ra. ed. italiana, Einaudi, 1964.)

CHABOD, Federico, "El secretario florentino" (1953), en F. CHABOD, Escritos sobre Maquiavelo. Trad. de Rodrigo RUZA. México, FCE, 1984. (1 ra. ed. italiana, Einaudi, 1964.)

DURÁN, Agustín, "Prólogo", Romancero general. Madrid, Rivadeneyra, 1849. 2 tt. (BAE, t. X), t. I. (Ira. ed., 1828-1832.)

HEGEL, G. W. F., Werke, t. X, pp. 231 y ss. Cit. por Ernst BLOCH, Sujetoobjeto. El pensamiento de Hegel. México, FCE, 1983. 
HUIZINGA, Johan, Entre las sombras del mañana, Revista de Occidente. Madrid, 1936.

Huizinga, Johan, El otoño de la Edad Media. Trad. de José GaOs. Madrid, Alianza, 1978.

KOHN, Hans, Historia del nacionalismo. México, FCE, 1949.

KouzNETJOV, Boris G., "Estética de la ciencia no clásica", en Diógenes, núm. 115. México, UNESCO/UNAM, otoño de 1981. Trad. de María Ofelia ARRUTI.

LOVEJoY, Arthur O., The Great Chain of Being. A Study of the History of an Idea. Universidad de Harvard, 1936. (14a. reimpresión, 1978.)

LUKACS, Georg, El asalto a la razón. La trayectoria del irracionalismo desde Schelling hasta Hitler. Trad. de Wenceslao ROCES. México, FCE, 1959.

Mansilla, H. C. F., "Machiavelli y Hobbes, filósofos de la historia en la perspectiva de la Escuela de Frankfurt", en Introducción a la teoría critica de la sociedad. Barcelona, Seix-Barral, 1970.

MARTIN, Alfred von, Sociología del Renacimiento. Trad. de Manuel PEdroso. México, FCE, 1946. (Col. Popular, 40) (1 ra. ed. alemana, Stuttgart, 1932.)

MENÉNDez PElayo, Marcelino, Historia de las ideas estéticas, t. v. Madrid, CSIC.

PARDO BAZÁN, Emilia, Obras completas, vol. 37, La literatura francesa moderna. El romanticismo. Madrid, Biblioteca Renacimiento, 1911.

PRAZ, Mario, La carne, la muerte y el diablo en la literatura romántica. Caracas, Monte Ávila, 1970.

READ, Herbert, "La revolución romántica" (1954), en La décima musa. Ensayos de crítica. Buenos Aires, Infinito, 1972. 
SANCTIS, Francesco de, Historia de la literatura italiana (1870). Trad. de Ambrosio J. VECINO. Buenos Aires, Americalee, 1944.

SCHRADE, Hubert, German Romantic Painting. Nueva York, Abrams Publishers, 1977.

SYMONDS, J. A., El Renacimiento en Italia. México, FCE, 1957. 2 tt. II. (1 ra. ed. ingl., 1878-1886.)

TIEGHEM, Paul van, Le préromantisme: études d'historie littéraire européenne. París, 1948. 3 vols.

VALÉRY, Paul, Mauvaises pensées et autres, en Oeuvres. París, Letra "B", 1941 .

VALÉRY, Paul, Oeuvres. París, Gallimard/Pléiade, t. II. 1960. 3 tt.

WELLEK, René, "El concepto de romanticismo en la historia literaria", en Historia literaria. Problemas y conceptos. Barcelona, Laia, 1983, pp. 123-194. 